\title{
Screening for Psychotherapeutic Medication Misuse in Primary Care Patients: Comparing Two Instruments
}

\author{
Sebastian T. Tong, MD, MPH, Kathryn M. Polak, MS, Michael F. Weaver, MD, \\ Gabriela C. Villalobos, BS, Wally R. Smith, MD, and Dace S. Svikis, PhD
}

Introduction: Prescription psychotherapeutic medication misuse is a growing problem in the United States, but no method exists to routinely screen for this in primary care. Our study sought to (1) describe the prevalence of prescription psychotherapeutic medication misuse in primary care and the characteristics of patients who misuse and (2) compare 2 screening instruments modified to identify prescription medication misuse in primary care.

Methods: Primary care patients from underserved, urban clinics within a health system completed anonymous computer-directed health screens that included standard questions about prescription medication misuse. They were also administered the 4-item Cut down, Annoyed, Guilty, and Eye-opener questionnaire modified to focus on prescription medications (RxCAGE) and a 6-item Prescription Opioid Misuse Index (POMI-e) expanded to include other prescription medications.

Results: of 2,339 respondents, $15.3 \%$ were positive for at least 2 items on the RxCAGE and $18.6 \%$ were positive for at least 2 items on the POMI-e. Using our computer-directed health screen as a comparison, we found that POMI-e had a higher area under the curve (0.63). A positive POMI-e was associated with being male, white and unemployed, having depression and anxiety, and currently using illicit substances, smoking, and misusing alcohol.

Conclusions: Rates of prescription medication misuse were substantial with both RxCAGE and POMI-e showing promise as screening instruments. Future studies are needed to test prescription medication misuse screening tools in broader populations and pilot interventions for those screening positive. (J Am Board Fam Med 2019;32:272-278.)

Keywords: Drug Abuse, Prevalence, Primary Health Care, Psychotropic Drugs, Substance Abuse Detection

In 2016, an estimated 115 million Americans or $42.8 \%$ of the adult population used prescription psychotherapeutic drugs in the past year. Of those, an estimated 18.6 million or $16.2 \%$ misused prescription psychotherapeutic drugs. ${ }^{1-3}$ Misuse is defined by the National Survey on Drug Use and

This article was externally peer reviewed.

Submitted 12 June 2018; revised 5 November 2018; accepted 7 November 2018.

From Virginia Commonwealth University, Richmond, VA (STT, KMP, GCV, WRS, DSS); University of Texas Health Science Center at Houston, TX (MFW)

Funding: Funding for this study was provided by the National Institute on Drug Abuse (RO1 DA026091).

Conflict of interest: none declared.

Corresponding author: Sebastian T. Tong, MD, MPH, Virginia Commonwealth University, 830 E Main Street, Box 980101, Richmond, VA, 23298 (Email: sebastian.tc. tong@gmail.com).
Health (NSDUH) as medication use in any way not directed by a prescribing clinician, including using another's prescription, greater amounts, more often, or longer than directed. ${ }^{4}$ Current attention has focused heavily on the growing opioid epidemic. $^{2,5-7}$ As prescription opioid misuse continues to grow each year, overdose deaths from prescription opioids, the most commonly misused prescription drug, have almost quadrupled in the past decade and are paralleled by a similar increase in emergency department visits, falls, and fractures. ${ }^{8}$ Furthermore, the misuse of prescription opioids is a significant risk factor for future or concurrent heroin use. ${ }^{9,10}$

In addition to prescription opioid misuse, misuse of tranquilizers (defined as benzodiazepines and muscle relaxants), stimulants (such as amphet- 
amines), and sedatives is growing, albeit largely unrecognized. ${ }^{11-16}$ Although it is well known that tranquilizers, stimulants, and sedatives can have substantial negative effects that include fatal overdose in some cases, they have not been well-studied to date. ${ }^{13,16,17}$

Although recognizing prescription opioid misuse as a problem in the patients they are serving, ${ }^{18}$ primary care clinicians continue contributing to the growing problems with misuse by writing $45 \%$ of all opioid prescriptions ${ }^{19}$ and substantial proportions of benzodiazepines and other psychotherapeutic drugs. ${ }^{20,21}$ A few studies have documented the prevalence of prescription psychotherapeutic medication misuse in general primary care or community pharmacy settings, but studies to date have not documented the characteristics of patients who are likely to misuse prescription psychotherapeutic drugs and the prevalence of misuse in predominantly underserved primary care practices. ${ }^{22,23}$ Our study aimed to (1) describe the characteristics of primary care patients who misuse prescription psychotherapeutic agents and (2) compare rates of misuse obtained from 2 standardized screening tools modified to focus on prescription medication misuse.

\section{Methods}

\section{Participants and Data Collection}

We conducted a cross-sectional survey of patients in underserved, urban primary care clinics within a university-based health system. Clinics were located both adjacent to the hospital or at satellite, community sites. Patients were recruited in clinic waiting areas for an anonymous survey focused on health behaviors. Patients between the ages of 18 and 70 years who could understand English were eligible for the study. Interested participants were escorted to a private area adjacent to the clinic waiting room either before or after their scheduled medical appointments. After providing verbal consent, participants completed the 15-minute Health Cheq survey on a tablet computer, guided by a 3-D avatar (Peedy the Parrot) who read each question aloud and kept participants engaged in the process. $^{24,25}$ This was followed by a brief research assistant-administered survey. Patients received $\$ 10$ for their participation in the study. Data were collected between July 2012 and December 2013. This study was approved by the Virginia Commonwealth University Institutional Review Board.

\section{Outcome Measures}

Health Cheq collected information on patient demographics, general health behaviors, general medical concerns, mental health, and psychosocial issues. It also included 4 questions about prescription drug misuse in the past month: (1) taking more pills than prescribed, (2) taking pills more often than prescribed, (3) using medicine prescribed for someone else, or (4) getting the same medicine from more than 1 doctor. These questions were considered standard at the time and were based on the NSDUH questionnaire. Health Cheq also collected the standard Cut down, Annoyed, Guilty, and Eye-opener (CAGE) questionnaire for alcohol if male ${ }^{26}$ or the Tolerance, Annoyance, Cut down, and Eye-opener (TACE) questionnaire if female, ${ }^{27}$ as well as the CAGE Adapted to Include Drugs (CAGE-AID) for all illicit drugs. ${ }^{28}$ Research assistants then screened patients in person using 2 prescription drug misuse screening instruments: (1) prescription medication CAGE (RxCAGE), a 4-item screener, using CAGE alcohol use disorder items modified to focus on prescription drugs ${ }^{26}$ and (b) Prescription Opioid Misuse Index (POMI-e), expanded from the original focus on prescription opioid misuse to include all prescription drugs. ${ }^{29}$

\section{Data Analysis}

Using SPSS v22, item frequencies and scale scores for the 2 screening instruments were calculated. Sensitivity and specificity were calculated, along with a receiver operating characteristic curve analysis to calculate area under the curve (AUC), for cutoff scores of 1 and 2 in both RxCAGE and POMI-e. The anonymous Health Cheq questions that were standard care at the time were used for comparison, because they were computer administered. McNemar tests were then used to test for associations between the screening instrument and cutoff score with the highest AUC with demographic, medical, mental health, and substance use characteristics, as identified in Health Cheq.

\section{Results}

\section{Respondent Characteristics}

A total of 2,339 patients participated in the study (Table 1). The mean age was 46 , with $61.7 \%$ of respondents who were female and $70.5 \%$ identified as African American. A total of $79.4 \%$ were unin- 
Table 1. Demographics of Respondents to Health Cheq Survey $(\mathrm{n}=2,339)$

\begin{tabular}{lcc}
\hline Demographic & $\mathrm{n}(\%)$ & Mean $(\mathrm{SD})$ \\
\hline Age (years) & & \\
Ethnicity/Race & & \\
White & $567(24.5)$ \\
Black & $1,648(70.5)$ & \\
Other & $124(5.3)$ \\
Sex & \\
Males & $897(38.3)$ \\
Females & $1,442(61.7)$ \\
Employment & $318(13.6)$ \\
Full Time & $1,035(44.2)$ \\
Unemployed & $969(41.4)$ \\
Other & $17(0.7)$ \\
Did not answer & \\
Marital Status & $1,021(43.7)$ \\
Single & $388(16.6)$ \\
In a relationship & $391(16.7)$ \\
Married & $439(18.8)$ \\
Divorced/Separated & $94(4)$ \\
Widowed & $6(0.3)$ \\
Did not answer & $170(7.3)$ \\
Insurance Type & $167(7.1)$ \\
Private & $144(6.2)$ \\
Medicare & \\
Medicaid & \\
Indigent Care & \\
None & \\
Did not answer & $(71.4)$ \\
\hline & \\
\hline
\end{tabular}

$\mathrm{SD}$, standard deviation.

sured with $71.6 \%$ of those receiving care through the health system's indigent care program.

\section{Screening Tools}

On the RxCAGE, $37.8 \%$ answered yes to at least 1 item and $15.3 \%$ answered yes to 2 or more items (Table 2). Feeling the need to cut down on the use of prescription drugs was the most frequently endorsed $(22.6 \%)$, followed by ever using prescription drugs to get going or calm down $(21.2 \%)$. On the POMI-e, $36.2 \%$ answered yes to at least 1 item and $18.6 \%$ to 2 or more items (Table 2). Ever feeling high or getting a buzz after using medication was the most frequently positive in POMI-e $(16.7 \%)$, followed by using medication more frequently than prescribed (15.7\%). When comparing RxCAGE and POMI-e as well as cutoff scores of 1 or higher and 2 or higher, POMI-e with a cutoff score of 2 or higher had the largest area under the curve (AUC) $(0.63, P<.001)$ (Table 3).

\section{Associations with Prescription Drug Misuse}

The POMI-e was used to characterize associations because it had the largest AUC with a cutoff score of 2 or more (hereafter referred to as a "positive POMI-e"). Multiple demographic characteristics along with medical, mental health, and substance use comorbidities were associated with a positive POMI-e (Table 4). Demographic characteristics associated with a positive POMI-e included being younger, male, white, and unemployed. Although arthritis was the only chronic condition with POMI-e positive and negative group differences (44.8\% vs $35.9 \%$ respectively, $P=.001$ ), POMI-e positive patients had a higher number of chronic diseases than POMI-e negative patients (1.62 vs 1.49 respectively, $P=.037$ ).

Both depression and anxiety independently were associated with a positive POMI-e. Likewise, lifetime cigarette use and current smoking status were associated with a positive POMI-e. Those who had used illicit drugs in the past 30 days as well as those who screened positive in the CAGE-AID were more likely to have a positive POMI-e. Furthermore, positive alcohol TACE for women, CAGE for men, or a positive CAGE-AID were more likely for the positive POMI-e group as compared with the negative POMI-e group $(64.1 \%$ vs $32.2 \%$ respectively, $P<.001)$.

\section{Discussion}

Substantial rates of prescription psychotherapeutic medication misuse were identified in this urban primary care population. The prevalence of prescription medication misuse was similar for the 2 instruments, but POMI-e had a higher AUC than RxCAGE. Given the high association of prescription drug misuse with mental health and substance use comorbidities, patients identified with prescription drug misuse might merit special attention in primary care. Routine screening for prescription drug misuse might have a substantial impact in reducing misuse if clinicians had evidence-based interventions for those who screened positive.

Future studies to validate and test implementation of the screening tools could have substantial impact on the way clinicians identify patients with prescription psychotherapeutic drug misuse. Fur- 
Table 2. Positive Screens from Prescription Drug Misuse Screening Instruments

\begin{tabular}{|c|c|c|c|c|c|}
\hline \multicolumn{4}{|c|}{$\begin{array}{l}\text { Research Assistant-Administered Screening Tools } \\
\text { RxCAGE (CAGE modified to focus on } \\
\text { prescription drug misuse) }\end{array}$} & \multicolumn{2}{|c|}{$\begin{array}{c}\text { Prescription misuse items } \\
n(\%)\end{array}$} \\
\hline Questions & n (\%) yes & Questions & n (\%) yes & Questions & yes \\
\hline $\begin{array}{l}\text { Have you ever felt the need } \\
\text { to Cut down on your use } \\
\text { of prescription drugs? }\end{array}$ & $528(22.6)$ & $\begin{array}{l}\text { Do you ever use more of your } \\
\text { medication, that is, take a } \\
\text { higher dose, than is } \\
\text { prescribed for you? }\end{array}$ & $350(15.0)$ & $\begin{array}{l}\text { Taken more pills } \\
\text { than the } \\
\text { doctor told } \\
\text { you to }\end{array}$ & $113(4.8)$ \\
\hline $\begin{array}{l}\text { Have you ever felt } \\
\text { Annoyed by remarks by } \\
\text { your friends or loved } \\
\text { ones made about your } \\
\text { use of prescription drugs? }\end{array}$ & $246(10.5)$ & $\begin{array}{l}\text { Do you ever use your } \\
\text { medication more often, that } \\
\text { is, shorten the time } \\
\text { between dosages, than is } \\
\text { prescribed for you? }\end{array}$ & $368(15.7)$ & $\begin{array}{l}\text { Taken pills more } \\
\text { often than the } \\
\text { doctor told } \\
\text { you }\end{array}$ & $74(3.2)$ \\
\hline $\begin{array}{l}\text { Have you ever felt Guilty } \\
\text { or remorseful about your } \\
\text { use of prescription drugs? }\end{array}$ & $219(9.4)$ & $\begin{array}{l}\text { Do you ever need early refills } \\
\text { for your medication? }\end{array}$ & $274(11.7)$ & $\begin{array}{l}\text { Used medicine } \\
\text { prescribed for } \\
\text { someone else }\end{array}$ & $91(3.9)$ \\
\hline \multirow[t]{3}{*}{$\begin{array}{l}\text { Have you Ever used } \\
\text { prescription drugs as a } \\
\text { way to "get going" or } \\
\text { "calm down?" }\end{array}$} & $497(21.2)$ & $\begin{array}{l}\text { Do you ever feel high or get a } \\
\text { buzz after using your } \\
\text { medication? }\end{array}$ & $390(16.7)$ & $\begin{array}{l}\text { Got the same } \\
\text { medicine from } \\
\text { more than one } \\
\text { doctor }\end{array}$ & $18(0.8)$ \\
\hline & & $\begin{array}{l}\text { Do you ever take your } \\
\text { medication because you are } \\
\text { upset, using the medication } \\
\text { to relieve or cope with } \\
\text { problems other than pain? }\end{array}$ & $260(11.1)$ & & \\
\hline & & $\begin{array}{l}\text { Have you ever gone to } \\
\text { multiple physicians, } \\
\text { including emergency room } \\
\text { doctors, seeking more of } \\
\text { your medication? }\end{array}$ & $99(4.2)$ & & \\
\hline$\geq 1$ item(s) positive & $884(37.8)$ & $\geq 1$ item(s) positive & $847(36.2)$ & $\begin{array}{l}\geq 1 \text { item(s) } \\
\text { positive }\end{array}$ & $180(7.7)$ \\
\hline$\geq 2$ items positive & $358(15.3)$ & $\geq 2$ items positive & 435 (18.6) & $\begin{array}{r}\geq 2 \text { items } \\
\text { positive }\end{array}$ & $81(3.5)$ \\
\hline
\end{tabular}

RxCAGE, Cut down, Annoyed, Guilty, and Eye-opener questionnaire modified to focus on prescription medications; POMI-e, Prescription Opioid Misuse Index expanded to include all prescription medications.

thermore, successful interventions to treat patients identified with misuse and at risk of medication harm will need to be tested in primary care settings. To be successfully implemented, the development of validated screening tools and evidence-based in- terventions should be combined with clinician education in prescription drug misuse.

Several limitations exist. First, participants were all from urban, underserved primary care clinics, and only English speakers were included, which

Table 3. Sensitivity, Specificity, and ROC curve analyses for Rx-CAGE and POMI-e

\begin{tabular}{lccccrr}
\hline Measure & $\begin{array}{c}\text { Cut off score } \\
\text { (equal or } \\
\text { higher than) }\end{array}$ & Sensitivity* $(\%)$ & Specificity* $(\%)$ & AUC & $95 \%$ CI & $P$ value \\
\hline Rx-CAGE & 1 & 62.8 & 64.3 & 0.54 & $0.52-0.57$ & .001 \\
& 2 & 35.6 & 86.4 & 0.56 & $0.53-0.60$ & $<.001$ \\
POMI-e & 1 & 82.8 & 67.7 & 0.58 & $0.55-0.60$ & $<.001$ \\
& 2 & 69.4 & 85.6 & 0.63 & $0.60-0.66$ & $<.001$ \\
\hline
\end{tabular}

ROC, receiver operating characteristic; CI, confidential interval; AUC, area under the curve; RxCAGE, Cut down, Annoyed, Guilty, and Eye-opener questionnaire modified to focus on prescription medications; POMI-e, Prescription Opioid Misuse Index expanded to include all prescription medications.

${ }^{*}$ Having 1 or more positive Health Cheq Rx misuse items was used as the comparison. 
Table 4. Participant Characteristics of Those at Risk for Prescription Misuse Based on POMI-e Scores of $\geq 2$

\begin{tabular}{|c|c|c|c|c|c|}
\hline \multirow[b]{2}{*}{ Characteristics } & \multicolumn{2}{|c|}{$\begin{array}{l}\text { POMI-e }<2 \text { items endorsed } \\
\qquad(\mathrm{n}=1904)\end{array}$} & \multicolumn{2}{|c|}{$\begin{array}{l}\text { POMI-e } \geq 2 \text { items } \\
\text { endorsed }(n=435)\end{array}$} & \multirow[b]{2}{*}{$P$ value } \\
\hline & $\mathrm{n}(\%)$ & Mean (SD) & n (\%) & Mean (SD) & \\
\hline \multicolumn{6}{|l|}{ Demographic Characteristics } \\
\hline Age & & $46.43(11.72)$ & & $44.8(10.39)$ & .004 \\
\hline \multicolumn{6}{|l|}{ Gender } \\
\hline Male & $694(36.4)$ & & $203(46.7)$ & & $<.001$ \\
\hline Female & $1210(63.6)$ & & $232(53.3)$ & & \\
\hline \multicolumn{6}{|l|}{ Race } \\
\hline White & $429(22.5)$ & & $138(31.7)$ & & $<.001$ \\
\hline Black & $1370(72.0)$ & & $278(63.9)$ & & \\
\hline Other & $105(5.5)$ & & $19(4.4)$ & & \\
\hline \multicolumn{6}{|l|}{ Employment* } \\
\hline Full time & $273(14.5)$ & & $45(10.4)$ & & .015 \\
\hline Unemployed & $818(43.3)$ & & $217(50.0)$ & & \\
\hline Other & $797(42.2)$ & & $172(39.6)$ & & \\
\hline \multicolumn{6}{|l|}{ Education* } \\
\hline Less than high school & $429(23.3)$ & & $111(26.1)$ & & .132 \\
\hline High school & $694(37.7)$ & & $171(40.1)$ & & \\
\hline College/advanced degree/technical training & $717(39.0)$ & & $144(33.8)$ & & \\
\hline \multicolumn{6}{|l|}{ Medical Characteristics } \\
\hline \multicolumn{6}{|l|}{ Chronic Diseases } \\
\hline Hypertension & $1034(54.3)$ & & $225(51.7)$ & & .330 \\
\hline Heart disease & $209(11.0)$ & & $225(51.7)$ & & .702 \\
\hline Asthma & $448(23.5)$ & & $116(26.7$ & & .170 \\
\hline Chronic obstructive pulmonary disease & $211(11.1)$ & & $54(12.4)$ & & .430 \\
\hline Arthritis & $683(35.9)$ & & $195(44.8)$ & & .001 \\
\hline Migraines & $253(13.3)$ & & $71(16.3)$ & & .098 \\
\hline Any chronic disease & $1471(77.3)$ & & $351(80.7)$ & & .12 \\
\hline Sum number of chronic diseases & & $1.49(1.19)$ & & $1.62(1.22)$ & .037 \\
\hline \multicolumn{6}{|l|}{ Past 30 days sleep rating } \\
\hline Very good & $209(11.0)$ & & $18(4.1)$ & & $<.001$ \\
\hline Good & $514(27.0)$ & & $63(14.5)$ & & \\
\hline Fair & $699(36.7)$ & & $179(41.1)$ & & \\
\hline Poor & $482(25.3)$ & & $175(40.2)$ & & \\
\hline \multicolumn{6}{|l|}{ Overall health rating } \\
\hline Very good or excellent & $447(23.5)$ & & $65(14.9)$ & & $<.001$ \\
\hline Good & $708(37.2)$ & & $165(37.9)$ & & \\
\hline Fair or poor & $749(39.3)$ & & $205(47.1)$ & & \\
\hline \multicolumn{6}{|l|}{ Mental Health Characteristics } \\
\hline Anxiety & $514(27.0)$ & & $212(48.7)$ & & $<.001$ \\
\hline Depression & $633(33.2)$ & & $242(55.6)$ & & $<.001$ \\
\hline \multicolumn{6}{|l|}{ Substance Use Characteristics } \\
\hline \multicolumn{6}{|l|}{ Lifetime cigarette use* } \\
\hline Smoked $\geq 100$ cigarettes & $806(42.4)$ & & $276(63.7)$ & & $<.001$ \\
\hline Smoked $<100$ cigarettes & $410(21.6)$ & & $76(17.6)$ & & \\
\hline Never smoked & $685(36.0)$ & & $81(18.7)$ & & \\
\hline
\end{tabular}




\begin{tabular}{|c|c|c|c|c|c|}
\hline \multirow[b]{2}{*}{ Characteristics } & \multicolumn{2}{|c|}{$\begin{array}{l}\text { POMI-e }<2 \text { items endorsed } \\
\qquad(\mathrm{n}=1904)\end{array}$} & \multicolumn{2}{|c|}{$\begin{array}{l}\text { POMI-e } \geq 2 \text { items } \\
\text { endorsed }(\mathrm{n}=435)\end{array}$} & \multirow[b]{2}{*}{$P$ value } \\
\hline & n $(\%)$ & Mean (SD) & $\mathrm{n}(\%)$ & Mean (SD) & \\
\hline Current smoker & $757(39.8)$ & & $280(64.4)$ & & $<.001$ \\
\hline \multicolumn{6}{|l|}{ Illicit drug use } \\
\hline Past 30 days illicit drug use & $157(8.2)$ & & $121(27.8)$ & & $<.001$ \\
\hline CAGE-AID positive ( $\geq 1$ positive) & $117(6.1)$ & & $110(25.3)$ & & $<.001$ \\
\hline \multicolumn{6}{|l|}{ Alcohol use } \\
\hline $\begin{array}{l}\geq 2 \text { TACE }+ \text { with women or } \geq 1 \text { CAGE }+ \text { with } \\
\text { men }\end{array}$ & $226(25.5)$ & & $132(51.6)$ & & $<.001$ \\
\hline $\begin{array}{l}\text { Positive for illicit drugs (as measured by CAGE-AID) } \\
\text { or alcohol (as measured by } \geq 2 \text { TACE for } \\
\text { women or } \geq 1 \text { CAGE for men) }\end{array}$ & $285(32.2)$ & & $164(64.1)$ & & $<.001$ \\
\hline
\end{tabular}

CAGE, Cut down, Annoyed, Guilty, and Eye-opener; CAGE-AID, CAGE Adapted to Include Drugs; TACE, Tolerance, Annoyance, Cut down, and Eye-opener; SD, standard deviation; POMI-e, Prescription Opioid Misuse Index expanded to include all prescription medications.

*Nonresponders to these survey questions were not included in the analysis.

may limit the generalizability to the general population. This may be mitigated by the large sample size. Second, those who have more difficulty with using a computer-administered screening tool or have poor literacy may not have answered the questions or declined participation in the study. Third, there may be a response bias because a research assistant administered instruments with patients knowing that results would not be shared with their clinician. Patients may respond differently if these screening tools were administered in person by their clinicians.

\section{Conclusions}

Both RxCAGE and POMI-e show promise as screening tools for prescription psychotherapeutic medication misuse and warrant further study. Developing and implementing validated screening tools for prescription psychotherapeutic medication misuse may help primary care clinicians identify and care for patients with prescription drug misuse and reduce the morbidity, societal impacts, and costs of the current prescription drug misuse epidemic.

To see this article online, please go to: http://jabfm.org/content/ 32/2/272.full.

\section{References}

1. Substance Abuse and Mental Health Services Administration. Results from the 2016 National Survey on Drug Use and Health: detailed tables. https:// www.samhsa.gov/data/sites/default/files/NSDUH-
DetTabs-2016/NSDUH-DetTabs-2016.pdf. Published 2017. Accessed May 29, 2018.

2. Han B, Compton WM, Blanco C, Crane E, Lee J, Jones CM. Prescription opioid use, misuse, and use disorders in U.S. adults: 2015 National Survey on Drug Use and Health. Ann Intern Med 2017;167: 293-301.

3. Han B, Compton WM, Jones CM, Cai R. Nonmedical prescription opioid use and use disorders among adults aged 18 through 64 years in the united states, 2003-2013. JAMA 2015;314:1468-78.

4. Jordan BK, Karg RS, Batts KR, Epstein JF, Wiesen C. A clinical validation of the National Survey on Drug Use and Health assessment of substance use disorders. Addict Behav 2008;33:782-98.

5. Office of the Surgeon General. Facing addiction in america: the surgeon general's report on alcohol, drugs, and health. Washington, D.C.: U.S. Department of Health and Human Services; 2016.

6. Dowell D, Haegerich TM, Chou R. CDC guideline for prescribing opioids for chronic pain-United States, 2016. JAMA 2016;315:1624-45.

7. Quinones S. Dreamland: the true tale of America's opiate epidemic. New York, NY: Bloomsbury Press; 2016.

8. Substance Abuse and Mental Health Services Administration. Prescription drug misuse and abuse. http:// www.samhsa.gov/prescription-drug-misuse-abuse. Published 2017. Accessed June 4, 2018.

9. Jones CM. Heroin use and heroin use risk behaviors among nonmedical users of prescription opioid pain relievers - United States, 2002-2004 and 20082010. Drug Alcohol Depend 2013;132:95-100.

10. Cicero TJ, Ellis MS, Surratt HL, Kurtz SP. The changing face of heroin use in the United States: a 
retrospective analysis of the past 50 years. JAMA Psychiatry 2014;71:821-6.

11. Hughes A, Williams M, Lipari R, Bose J, Copello E, Kroutil L. Prescription drug use and misuse in the United States: results from the 2015 National Survey on Drug Use and Health. Substance Abuse and Mental Health Services Administration; 2016.

12. Mack KA, Zhang K, Paulozzi L, Jones C. Prescription practices involving opioid analgesics among Americans with Medicaid, 2010. J Health Care Poor Underserved 2015;26:182-98.

13. Maree RD, Marcum ZA, Saghafi E, Weiner DK, Karp JF. A systematic review of opioid and benzodiazepine misuse in older adults. Am J Geriatr Psychiatry 2016;24:949-63.

14. Murphy Y, Wilson E, Goldner EM, Fischer B. Benzodiazepine use, misuse, and harm at the population level in Canada: a comprehensive narrative review of data and developments since 1995. Clin Drug Investig 2016;36:519-30.

15. Panes A, Lassalle R, Bernard M-A, DureaudPournin C, Pariente A, Fourrier-Reglat A. Misuse of benzodiazepines in the French population: A cohort study in the Échantillon Genéraliste de Bénéficiaires between 2007 and 2012. Revue Épidémiol Santé Publique 64:S132-S133, 2016.

16. Bachhuber MA, Hennessy S, Cunningham CO, Starrels JL. Increasing benzodiazepine prescriptions and overdose mortality in the United States, 19962013. Am J Public Health 2016;106:686-8.

17. Khanra S. Benzodiazepine misuse: when shall we wake up? Asian J Psychiatr 2017;29:134-5.

18. Hwang CS, Turner LW, Kruszewski SP, Kolodny A, Alexander GC. Primary care physicians' knowledge and attitudes regarding prescription opioid abuse and diversion. Clin J Pain 2016;32:279-84.

19. Levy B, Paulozzi L, Mack KA, Jones CM. Trends in opioid analgesic-prescribing rates by specialty, U.S., 2007-2012. Am J Prev Med 2015;49:409-13.
20. Kroll DS, Nieva HR, Barsky AJ, Linder JA. Benzodiazepines are prescribed more frequently to patients already at risk for benzodiazepine-related adverse events in primary care. J Gen Intern Med 2016;31: 1027-34.

21. Park TW, Saitz R, Nelson KP, Xuan Z, Liebschutz $\mathrm{JM}$, Lasser KE. The association between benzodiazepine prescription and aberrant drug-related behaviors in primary care patients receiving opioids for chronic pain. Subst Abus 2016;37:516-20.

22. Cochran G, Rubinstein J, Bacci JL, Ylioja T, Tarter R. Screening community pharmacy patients for risk of prescription opioid misuse. J Addict Med 2015;9: 411-6.

23. Bradley KA, Lapham GT, Caldeiro R, Marx L. Single-item screens for prescription and illicit drug misuse largely identifies primary care patients with unrecognized drug use. J Patient-Centered Res Rev 2:132, 2015.

24. Ondersma SJ, Chase L, Svikis DS, Schuster CR. Computer-based brief intervention for perinatal drug use. J Subst Abuse Treat 2005;28:305-12.

25. Breland AB, Almond L, Kienzle J, Ondersma SJ, Hart A Jr., Weaver M, Dillon P, Svikis D. Targeting tobacco in a community-based addiction recovery cohort: Results from a computerized, brief, randomized intervention trial. Contemp Clin Trials 2014; 38:113-20.

26. Ewing JA. Detecting alcoholism. The CAGE questionnaire. JAMA 1984;252:1905-7.

27. Stevenson JS, Masters JA. Predictors of alcohol misuse and abuse in older women. J Nurs Scholarsh 2005;37:329-35.

28. Brown RL, Rounds LA. Conjoint screening questionnaires for alcohol and other drug abuse: criterion validity in a primary care practice. Wis Med J 1995; 94:135-40.

29. Knisely JS, Wunsch MJ, Cropsey KL, Campbell ED. Prescription Opioid Misuse Index: a brief questionnaire to assess misuse. J Subst Abuse Treat 2008;35: 380-6. 